Disponível em

http://www.anpad.org.br/rac

RAC, Rio de Janeiro, v. 19, n. 5, art. 5, pp. 626-648, Set./Out. 2015

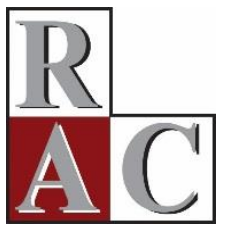

\title{
A Influência do Constrangimento do Consumidor no Processo de Compra
}

The Influence of Consumer Embarrassment on the Purchase Process

Giuliana Isabella

Universidade de São Paulo - USP/FEA

Lucia Salmonson Guimarães Barros Fundação Getulio Vargas - FGV/EBAPE

José Afonso Mazzon Universidade de São Paulo - USP/FEA

Artigo recebido em 23.04.2014. Última versão recebida em 17.03.2015. Aprovado em 23.03.2015. 


\title{
Resumo
}

O constrangimento é uma emoção que emerge em várias situações de compra e de consumo. Faltam estudos que abordem de forma abrangente como o consumidor se comporta no momento que está constrangido. Por isso, o objetivo deste artigo é mapear como o consumidor age durante o processo de compra em situações que geram constrangimento. Para isso, foi escolhido o varejo farmacêutico, onde é possível comprar uma série de produtos que podem causar constrangimento, como preservativos, testes de gravidez, pílula do dia seguinte, entre outros. Como estratégia de investigação empírica, entrevistas em profundidade com 30 balconistas de farmácia e 26 consumidores foram realizadas. A análise de conteúdo efetuada propiciou a elaboração de um framework conceitual e um conjunto de proposições. De acordo com o framework, o consumidor, ao se sentir constrangido, decide se abandona a compra (desistindo ou pedindo para outra pessoa fazê-la) ou se encara a situação; se optar por encarar a situação, toma coragem e desenvolve estratégias para enfrentá-la e terminá-la o mais breve possível. As ações dos consumidores são detalhadas neste framework.

Palavras-chave: comportamento do consumidor; constrangimento; emoção; processo de compra; varejo.

\begin{abstract}
Embarrassment is an emotion that emerges during various purchase and consumption situations. There is a lack of studies comprehensively addressing how consumers behave when they are embarrassed. Therefore, the aim of this paper is to map how consumers behave during purchase process situations that cause embarrassment. To do so, drugstores were selected since they are places where a number of products that can cause embarrassment, such as condoms, pregnancy tests, and day-after pills, can be purchased. In-depth interviews with 30 drugstore sales representatives and 26 consumers were conducted using an empiric investigation strategy. Content analysis resulted in the creation of a conceptual framework and some theoretical propositions. According to the framework, consumers, when feeling embarrassed, decide whether to abandon the purchase (by giving up or asking someone else to make the purchase) or if they face the situation, remain confident, and develop strategies to deal with the situation and finish it as soon as possible. The framework details consumers' actions.
\end{abstract}

Key words: consumer behavior; embarrassment; emotion; purchase process; retail. 


\section{Introdução}

O estudo das emoções vem ganhando cada vez mais importância no comportamento do consumidor (Laros \& Steenkamp, 2005; Sauerbronn, Ayrosa, \& Barros, 2009), pois elas atuam como antecedentes de uma série de comportamentos de compra e consumo (Dahl, Manchanda, \& Argo, 2001). Nesse contexto, uma parte importante da literatura de marketing aponta o papel de emoções específicas, como o medo (Tanner, Hunt, \& Eppright, 1991), a culpa (Duhachek, Agrawal, \& Han, 2012) e a raiva (Rucker \& Petty, 2004) na tomada de decisões do consumidor.

Entre as emoções específicas, alguns autores apontam o constrangimento como emoção que emerge em várias situações de compra e de consumo (Grace, 2007, 2009; Lau-Gesk \& Drolet, 2008). Grande parte da literatura sobre constrangimento pode ser dividida em três temas: (a) situações de compra e consumo que antecedem o constrangimento (Blair \& Roese, 2013; Brumbaugh \& Rosa, 2009; Dahl et al., 2001; Picca \& Joos, 2009), (b) situações em que o consumidor age para evitar experimentar esta emoção no futuro (Bell, 2009; Grace, 2007; Miller, 2001) e (c) como o consumidor se comporta no momento em que está constrangido (Brackett, 2004; Ekebas \& Arndt, 2015; Picca \& Joos, 2009).

Dentro do terceiro tema, a maior parte dos artigos aborda um único produto - por exemplo, a compra de preservativos (Moore, Dahl, Gorn, \& Weinberg, 2006; Moore et al., 2008; Picca \& Joos, 2009), ou uma situação de compra específica - por exemplo, o uso de cupons (Brumbaugh \& Rosa, 2009). No entanto, faltam na literatura estudos mais abrangentes que identifiquem, de forma integrada, como o consumidor se comporta em momentos que está constrangido.

Desta forma, este artigo procura preencher essa lacuna, estendendo e enriquecendo a literatura de constrangimento no comportamento do consumidor. Especificamente, este estudo mapeia como o consumidor age durante o processo de compra em situações que geram constrangimento.

Nesse contexto, o varejo farmacêutico foi escolhido como ambiente de estudo. Esta foi uma opção apropriada, uma vez que ambientes sociais carregam a capacidade de criar essa emoção (Grace, 2007; Nichols, Raska, \& Flint, 2012). Além disso, ao pensar em produtos que possam causar constrangimento, os produtos apontados pela literatura - preservativos, laxantes, fraldas geriátricas, anticoncepcionais e medicamentos para disfunção erétil - são encontrados em farmácias (Dahl et al., 2001; Picca \& Joos, 2003).

Assim, para explorar como os consumidores se comportam nesses momentos de constrangimento, uma pesquisa empírica foi realizada, derivando-se dela a elaboração de um framework conceitual e um conjunto de proposições de pesquisa. Utilizou-se a metodologia qualitativa, operacionalizada por meio da técnica de entrevistas em profundidade com balconistas de farmácia e consumidores de produtos associados a situações de constrangimento. A análise de conteúdo permitiu a identificação de um processo de compra influenciado por essa emoção.

\section{Referencial Teórico}

\section{Emoções no processo de compra}

Dentro do processo de compra, aspectos racionais e emocionais influenciam a tomada de decisões. Os aspectos racionais são levados em consideração principalmente na avaliação de benefícios tangíveis, como na compra de produtos utilitários, em que há a necessidade de solucionar um problema. Já as emoções influenciam principalmente a compra de produtos afetivos, hedônicos e experienciais, gerando comportamentos como a compra por impulso e a busca por variedade (Mowen, 1988). 
Uma forma de identificar a influência das emoções no comportamento do consumidor é em relação a sua valência (Russell, 1980). Sabe-se que as emoções positivas geram processamentos heurísticos (Isen \& Means, 1983), enquanto as negativas geram processamentos sistemáticos (Elsbach \& Barr, 1999). No processamento sistemático, os consumidores fazem avaliações mais detalhadas (por exemplo, dos atributos do produto) para realizar uma escolha (Elsbach \& Barr, 1999). Já no heurístico, aspectos gerais são levados em consideração e o consumidor usa atalhos (por exemplo, marca) para tomar uma decisão de compra (Isen \& Means, 1983). O processamento heurístico também ocorre quando os recursos de processamento de informação são limitados (por exemplo, quando o consumidor está processando outra informação no momento da escolha) (Shiv \& Fedorikhin, 1999).

Além da separação por valência, sabe-se que as emoções são diferentes em outras dimensões (Smith \& Ellsworth, 1985) e, com isso, emoções diferentes de mesma valência podem influenciar o comportamento de compra de formas distintas (Lench, Flores, \& Bench, 2011). Dentre as emoções negativas, o presente artigo foca a investigação no constrangimento.

\section{Constrangimento}

O constrangimento é uma emoção negativa (Watson \& Tellegen, 1985) que surge como consequência de uma autoavaliação (Izard, 1977; Keltner \& Buswell, 1996) e aparece em um contexto social (Feinberg, Willer, \& Keltner, 2012; Heller, 2003; La Taille, 2002). O constrangimento é uma emoção parecida com a vergonha, fazendo com que essas palavras muitas vezes sejam utilizadas como sinônimas (Izard, 1977). Essa emoção faz parte de uma tríade: vergonha, constrangimento e culpa, pertencendo a uma mesma dimensão de sentimentos, sendo assim, muitas vezes confundidas entre si (Sabini, Garvey, \& Hall, 2001). Grace (2007) complementa que o consumidor constrangido pode ter sentimentos de humilhação, tristeza, frustração, medo, depressão e raiva, além de se sentir estúpido, desconfortável e até mesmo sem autocontrole.

O constrangimento evoca reações fisiológicas, como mudanças no batimento cardíaco, na temperatura da pele, em expressões faciais, na vocalização e na postura, podendo provocar náuseas ou tremores (Gerlach, Roth, \& Frank, 2003; Verbeke \& Bagozzi, 2002). Por isso, é reconhecido por outras pessoas (Grace, 2007), que percebem indícios de rosto corado, comportamento desajeitado, gaguejo, suor, cabeça e olhos baixos (Heller, 2003; Miller, 2001).

O constrangimento pode ser classificado em dois tipos: avaliativo e expositivo (Lewis \& Ramsay, 2002). O constrangimento avaliativo acontece como resultado de uma avaliação negativa que um indivíduo faz de seu comportamento em face de um determinado padrão, regra ou objetivo. Uma vez que o constrangimento é consequência de uma autoavaliação negativa, alguns autores consideram-no uma forma de vergonha menos intensa (Higuchi \& Fukada, 2002; Izard, 1977). Já o constrangimento expositivo reflete simplesmente a exposição do indivíduo à atenção de outros (Lewis, Stanger, Sullivan, \& Barone, 1991).

Alguns autores comparam o constrangimento à vergonha. Por exemplo, Keltner e Buswell (1996) explicam que o constrangimento é associado à transgressão de convenções que governam as interações públicas, enquanto a vergonha é associada ao fracasso em atingir padrões pessoais. Ou seja, a vergonha é um estado emocional negativo onde o eu é o centro, enquanto no caso do constrangimento, o eu, embora presente, não seja foco central. O sujeito entende, no caso de vergonha, que ele é mau (Verbeke \& Bagozzi, 2002), enquanto no caso do constrangimento, que fez algo ruim (Lewis \& Ramsay, 2002).

As causas de cada uma dessas emoções também podem diferir. Um indivíduo não sente vergonha por ter atingido sucesso, mas pode experimentar a sensação de constrangimento por se sentir exposto, por exemplo, se parabenizado em público (Lewis \& Ramsay, 2002). Já a vergonha pode ser experimentada inclusive quando a pessoa está sozinha (Verbeke \& Bagozzi, 2002). Seria o caso de um indivíduo ter vergonha por se sentir atraído por alguém de sua família.

Apesar da distinção na literatura entre constrangimento e vergonha, isso não acontece na linguagem do cotidiano. Enquanto em inglês as palavras embarrassment e shame são utilizadas para 
situações distintas (Keltner \& Buswell, 1996), coloquialmente os brasileiros parecem usar a palavra vergonha para se referir a ambos estados afetivos (Ferreira, 2011).

\section{Constrangimento em situações de compra e consumo}

Como mencionado, a literatura sobre constrangimento no comportamento de compra e consumo pode ser dividida em três temas, cujas principais características são descritas a seguir.

\section{Situações de compra e consumo que causam o constrangimento}

Desde a identificação da necessidade de um produto até o seu descarte, a literatura aponta situações que podem causar constrangimento nas diversas fases do processo de compra e consumo. Essas fases incluem a identificação da necessidade (por exemplo, de preservativos), a busca de informações (perguntar ao balconista), as situações de compra (de revistas pornográficas em banca), pagamento (quando o cartão de crédito é recusado), uso de produtos e serviços (serviço de depilação ou de motel) e descarte (dispositivo de teste de gravidez) (Blair \& Roese, 2013; Brackett, 2004; Lau-Gesk \& Drolet, 2008; Nichols et al., 2012; Picca \& Joos, 2009).

Situações como essas geram constrangimento por dois diferentes mecanismos. O primeiro é a simples presença de outras pessoas (Dahl et al., 2001), como em uma loja cheia (Grace, 2007), ou a percepção de ser o centro das atenções (Lewis \& Ramsay, 2002). Neste caso, trata-se do constrangimento expositivo (Lewis \& Ramsay, 2002), em que o consumidor se sente desconfortável pela sensação de ser observado. O segundo é a percepção de ser julgado ou avaliado pelas pessoas que o observam, chamado constrangimento avaliativo (Lewis \& Ramsay, 2002). Neste caso, comprar um produto que contradiz a imagem que o consumidor quer passar aos outros pode gerar constrangimento quando a compra é observável (Dahl et al., 2001; Keltner \& Buswell, 1997; Lau-Gesk \& Drolet, 2008). Por exemplo, o consumidor se sente constrangido ao usar cupons ao antecipar o que o caixa pode pensar (Brumbaugh \& Rosa, 2009) ou quando tem que comprar produtos como preservativos, pensando que os outros podem avaliá-lo como promíscuo (Dahl et al., 2001; Lupton, 1994), ou quando o produto evidencia uma situação inconveniente, como por exemplo, diarreia (Blair \& Roese, 2013).

\section{Situações para evitar experimentar o constrangimento no futuro}

Por ser uma emoção desconfortável e perturbadora (Miller, 2001), pensar em situações que causam constrangimento pode gerar medo, já que é uma emoção que causa aversão (Verbeke \& Bagozzi, 2002). Com o objetivo de evitar essas situações, os consumidores alteram seus comportamentos e suas ações. Por exemplo, as pessoas constrangidas tendem a apresentar-se mais educadas, respeitosas, honestas e doadoras durante uma interação social (Miller, 2001).

No varejo, um consumidor que antecipa a situação de ter seu cartão de crédito recusado pode preferir pagar a compra em dinheiro, enquanto um consumidor que sabe que uma loja está cheia em determinado horário pode preferir fazer suas compras mais tarde (Lau-Gesk \& Drolet, 2008). No momento da compra, os indivíduos podem escolher determinados produtos (como absorventes higiênicos, enxaguatórios bucais, desodorantes e medicamentos para acne) com o intuito de evitar situações constrangedoras (como um sangramento menstrual à mostra ou o mau cheiro do corpo) (LauGesk \& Drolet, 2008) ou podem deixar de utilizar serviços que possam criar situações constrangedoras, como fazer exames de próstata (Miller, 2001).

Da mesma forma, se o produto a ser comprado causa constrangimento, o consumidor pode evitar comprá-lo ou, pelo menos, evitar comprar mais de um tipo de produto constrangedor na mesma ida ao ponto de venda (Bell, 2009). Se a expectativa de uma loja cheia causa essa emoção, o consumidor pode preferir lojas mais vazias, mudando de ponto de venda ou de horário (Brackett, 2004). Ele pode ainda buscar comprar produtos pela Internet ou vending machines, onde não há contato com outras pessoas (Grace, 2007). 


\section{Influência do constrangimento em situações de compra e de consumo}

O terceiro tema refere-se a estudos que descrevem o comportamento do consumidor no momento em que vivencia a sensação de constrangimento. A maior parte deles concentra-se em explicar: (a) o efeito do constrangimento na compra ou uso de um único produto; ou (b) descrever como o consumidor constrangido age numa situação de compra específica.

O principal produto abordado pela literatura neste tema é o preservativo. De acordo com os estudos de Brackett (2004) e Picca e Joos (2009), que investigaram estudantes universitários por meio de narrativas com papel e caneta, as estratégias para lidar com o constrangimento incluem monitorar se há outros consumidores na loja, evitar pedir ajuda aos vendedores e esconder o produto. Moore Dahl, Gorn e Weinberg (2006) e Moore et al. (2008), por meio de survey, complementam esses achados, demonstrando que consumidores canadenses, chineses e coreanos utilizam estratégias similares para lidar com o impacto do constrangimento na compra de preservativos.

Já os estudos que abordam situações específicas utilizam-se de pesquisa quantitativa, por meio de survey ou método experimental. Dentre eles, Brumbaugh e Rosa (2009) suportaram a hipótese de que o consumidor constrangido em relação à utilização de cupons de desconto tende a reduzir sua utilização nas lojas. Nichols, Raska e Flint (2012) encontraram que um maior nível de constrangimento aumenta o número de produtos que o consumidor coloca na cesta de compras. Por fím, Ekebas e Arndt (2015) explicam que os consumidores constrangidos escolhem vendedores do mesmo sexo e idade.

A exceção é o artigo de Grace (2007), que solicitou a participantes australianos a submeterem pela Internet textos sobre situações constrangedoras. A autora dá grande foco aos antecedentes do constrangimento e aos sentimentos dos consumidores, explorando também suas dimensões psicológica, emocional e comportamental.

Entretanto, faltam estudos para uma comparação simultânea entre diferentes situações e produtos. Também faltam análises sobre o processo de compra como um todo. Desta forma, o objetivo deste artigo é apresentar uma explicação integrada dos mecanismos utilizados pelo consumidor para lidar com o constrangimento.

\section{Método}

A pesquisa empírica foi operacionalizada por meio da técnica de entrevistas em profundidade com balconistas de farmácia (representando uma visão de fora ou de observador) e consumidores (representando uma visão de dentro ou de consumidor).

A coleta de dados foi feita em duas etapas. Primeiramente, foram realizadas 30 entrevistas com pessoas que trabalham em farmácias, nas funções de farmacêutico, gerente, balconista e atendente de cosméticos. Essas pessoas, por observar os compradores em seu dia-a-dia, podem, por meio de sua experiência, descrever situações nas quais clientes demonstraram sentir-se constrangidos. $\mathrm{O}$ mundo visto por meio dos olhos dos outros é rico, trazendo detalhes das situações vivenciadas e presenciadas no ambiente em estudo. As entrevistas foram realizadas em 23 farmácias, distribuídas em sete bairros da cidade de São Paulo. Em uma mesma semana, os autores desse artigo se deslocaram aos diferentes bairros buscando entrevistar pessoas que trabalham em diferentes portes e bandeiras de farmácias. Os bairros foram escolhidos para garantir diferenças socioeconômicas entre consumidores das farmácias. Nos bairros, ao se deparar com uma farmácia, os autores entraram para tentar realizar as entrevistas. Nesse processo, apenas duas lojas não autorizaram que seus profissionais fossem entrevistados. Importante salientar que ao abordar diferentes regiões e portes de farmácia, e pelo número de entrevistas realizadas, os autores tiveram uma visão mais global e diversificada do comportamento do consumidor constrangido. Na Tabela 1, apresenta-se o tipo de farmácia abordada e os produtos constrangedores descritos pelos entrevistados. 
Tabela 1

\section{Características dos Atendentes}

\begin{tabular}{|c|c|c|}
\hline Identificação & Tipo & Produtos Observados \\
\hline A01 & Independente & Medicamento para disfunção erétil, preservativo \\
\hline $\mathrm{A} 02$ & Rede & Preservativo, lubrificante íntimo \\
\hline $\mathrm{A} 03$ & Rede & Pílula do dia seguinte, medicamento para disfunção erétil, preservativo \\
\hline A04 & Rede & Medicamento para disfunção erétil, medicamento para hemorroida \\
\hline A05 & Rede & Medicamento para disfunção erétil, xilocaína para uso retal \\
\hline A06 & Rede & Preservativo, teste de gravidez, laxante \\
\hline A07 & Rede & Medicamento para disfunção erétil, anticoncepcional \\
\hline A08 & Rede & Laxante, medicamento para hemorroida, espermicida, anticoncepcional \\
\hline A09 & Rede & Medicamento para disfunção erétil, lubrificante íntimo e laxante \\
\hline A10 & Rede & Preservativo, teste de gravidez, medicamento para disfunção erétil \\
\hline A11 & Rede & Pílula do dia seguinte, absorvente, medicamento para disfunção erétil \\
\hline A12 & Rede & Lubrificante íntimo, medicamento para disfunção erétil, preservativo, laxante \\
\hline A13 & Independente & Absorvente, preservativo \\
\hline A14 & Rede & Preservativo, medicamento para disfunção erétil, injeção nas nádegas \\
\hline A15 & Rede & Preservativo, lubrificante íntimo, absorvente, anticoncepcional \\
\hline A16 & Rede & Medicamento para disfunção erétil, preservativo, creme íntimo, supositório \\
\hline A17 & Rede & Medicamento para disfunção erétil, preservativo \\
\hline A18 & Rede & Teste de gravidez, injeção nas nádegas, laxante, teste de gravidez \\
\hline A19 & Rede & Medicamento para disfunção erétil, fralda geriátrica, anticoncepcional \\
\hline $\mathrm{A} 20$ & Independente & Xilocaína, medicamento para disfunção erétil, preservativo, absorvente \\
\hline $\mathrm{A} 21$ & Rede & Medicamento para disfunção erétil, absorvente, laxante, supositório \\
\hline A 22 & Rede & Pílula do dia seguinte, preservativo, absorvente \\
\hline $\mathrm{A} 23$ & Independente & Preservativo, absorvente, pílula do dia seguinte, anticoncepcional \\
\hline A24 & Independente & Medicamento para disfunção erétil, pílula do dia seguinte \\
\hline A 25 & Independente & Pílula do dia seguinte, preservativo, absorvente \\
\hline A26 & Rede & Medicamento para disfunção erétil, absorvente, pílula do dia seguinte \\
\hline A27 & Rede & Medicamento para disfunção erétil, preservativo \\
\hline A28 & Independente & Medicamento para disfunção erétil, absorvente \\
\hline A29 & Rede & Medicamento para disfunção erétil, absorvente, produtos para próteses \\
\hline $\mathrm{A} 30$ & Rede & Medicamento para disfunção erétil, preservativo, anticoncepcional \\
\hline
\end{tabular}

Os entrevistados foram definidos pelos próprios profissionais das farmácias. Os autores desse estudo, ao entrarem nas farmácias, solicitaram ao gerente ou responsável da loja permissão para entrevistar, de 30 a 40 minutos, um ou dois funcionários, dependendo do tamanho da farmácia, explicando que o objetivo da pesquisa era conhecer o comportamento de clientes da loja. Após definido quem seria o entrevistado, os autores, junto ao entrevistado, se deslocaram para um canto da farmácia que estivesse sem clientes e relativamente calmo. Em seguida, os participantes receberam informações 
sobre o estudo e consentiram participar, entendendo que as entrevistas seriam gravadas por meio de um aparelho de mp3 e que as informações da loja e pessoais seriam anônimas e protegidas.

A entrevista foi conduzida utilizando-se um roteiro semiestruturado desenvolvido com base na literatura de constrangimento e de processo de compra. O roteiro semiestruturado teve como objetivo guiar os entrevistadores às perguntas principais que respondem ao objetivo desse estudo. Algumas perguntas desse roteiro foram: Poderia nos descrever em detalhe, como um passo a passo, o que ocorre com um consumidor constrangido desde o momento em que ele entra na farmácia até quando sai do estabelecimento? Quando não comentado, $\mathbf{O}(\mathbf{a})$ senhor(a) acredita que os consumidores adquirem outros produtos além do item constrangedor? $\mathrm{Na}$ sua opinião, por que eles agem dessa forma? Perguntas complementares inerentes às circunstâncias momentâneas foram utilizadas.

Primeiramente, os pesquisadores realizaram perguntas gerais solicitando que o participante descrevesse o processo de compra de um remédio qualquer, por exemplo. Essas perguntas serviram também para deixar o profissional da farmácia mais à vontade com o pesquisador. No final da entrevista, para avaliar o conceito estudado, foi perguntado qual era a maneira de identificar consumidores constrangidos. Algumas das respostas, condizentes com a literatura (ex. Heller, 2003; Miller, 2001), apontam o reconhecimento do público atendente em identificar essa emoção, como as descritas a seguir: "Vêm falar pertinho de você para ninguém ouvir" (A4); "Chegam no canto" (A7); "Às vezes dá (para perceber que está constrangido), não olha muito na sua cara" (A12).

Na segunda etapa, foram realizadas 26 entrevistas com consumidores que passaram por situações de constrangimento no varejo farmacêutico, cujas características estão resumidas na Tabela 2. Isso foi feito para se ter uma visão de dentro, uma visão do consumidor sobre suas próprias experiências. Deste modo, buscou-se identificar as estratégias empregadas para lidar com essa emoção e entender seus significados e influências no comportamento. Os entrevistados foram recrutados de forma voluntária por meio de anúncios em mídias sociais, que é uma forma eficiente de encontrar participantes de diferentes características sociais e demográficas (Fenner et al., 2012; Ramo \& Prochaska, 2012), e pelo sistema de bola de neve, no qual entrevistados indicaram pessoas conhecidas para participarem (Vergara, 2008). Mais especificamente, os autores se inscreveram na comunidade de pílula do dia seguinte do Facebook, um dos produtos comentados pelos balconistas, e solicitaram permissão ao organizador para anunciar a pesquisa no grupo. No anúncio, foi pedido que pessoas que tivessem passado por alguma situação de constrangimento na compra de produtos em farmácia, independente de ser pílula do dia seguinte, entrassem em contato por mensagem privada e, caso não tivessem, que espalhassem o comunicado a seus amigos. Além disso, foi pedido aos entrevistados que indicassem outras pessoas para serem entrevistadas.

Tabela 2

\section{Características dos Consumidores}

\begin{tabular}{clcll}
\hline Identificação & Gênero & Idade & Cidade & Produto Adquirido \\
\hline C01 & Mulher & 30 & Recife - PE & Pílula do dia seguinte \\
C02 & Mulher & 29 & Porto Alegre - RS & Pílula do dia seguinte \\
C03 & Mulher & 29 & São Paulo - SP & Teste de gravidez \\
C04 & Homem & 32 & São Paulo - SP & Preservativo \\
C05 & Mulher & 26 & Cotia - SP & Teste de gravidez \\
C06 & Mulher & 32 & Osasco - SP & Antidepressivo \\
C07 & Mulher & 26 & São Paulo - SP & Pílula do dia seguinte \\
\hline
\end{tabular}


Tabela 2 (continuação)

\begin{tabular}{|c|c|c|c|c|}
\hline Identificação & Gênero & Idade & Cidade & Produto Adquirido \\
\hline $\mathrm{C} 08$ & Mulher & 35 & São Paulo - SP & Pílula do dia seguinte \\
\hline $\mathrm{C} 09$ & Homem & 26 & Salvador - BA & Absorvente \\
\hline $\mathrm{C} 10$ & Homem & 32 & São Paulo - SP & Antidepressivo \\
\hline $\mathrm{C} 11$ & Mulher & 31 & São Paulo - SP & Preservativo \\
\hline $\mathrm{C} 12$ & Homem & 30 & Rio de Janeiro - RJ & Preservativo \\
\hline $\mathrm{C} 13$ & Mulher & 30 & São Paulo - SP & Lubrificante íntimo \\
\hline $\mathrm{C} 14$ & Homem & 27 & São Paulo - SP & Espermicida \\
\hline $\mathrm{C} 15$ & Mulher & 47 & Campinas - SP & Injeção nas nádegas \\
\hline $\mathrm{C} 16$ & Mulher & 27 & Osasco - SP & Teste de gravidez \\
\hline $\mathrm{C} 17$ & Mulher & 29 & São Paulo - SP & Pílula do dia seguinte \\
\hline $\mathrm{C} 18$ & Mulher & 40 & Bauru - SP & Medicamento para piolhos \\
\hline C19 & Mulher & 29 & Unaí-MG & Ansiolítico \\
\hline $\mathrm{C} 20$ & Mulher & 28 & Fortaleza $-\mathrm{CE}$ & Camisinha feminina \\
\hline $\mathrm{C} 21$ & Mulher & 33 & Vinhedo - SP & Pílula do dia seguinte \\
\hline $\mathrm{C} 22$ & Mulher & 28 & São Paulo - SP & Teste de gravidez \\
\hline $\mathrm{C} 23$ & Homem & 28 & São Paulo - SP & Lubrificante íntimo \\
\hline $\mathrm{C} 24$ & Mulher & 35 & São Paulo - SP & Anticoncepcional e Vaselina \\
\hline $\mathrm{C} 25$ & Mulher & 29 & São Paulo - SP & Teste de gravidez \\
\hline $\mathrm{C} 26$ & Mulher & 31 & Rio de Janeiro - RJ & Pílula do dia seguinte \\
\hline
\end{tabular}

Após esse primeiro contato, as entrevistas foram marcadas em um dia e horário específico e foram realizadas por Skype, gravadas e sem a presença de webcam. O uso do Skype permitiu encontrar pessoas de diferentes regiões do Brasil, contribuindo para um aumento na generalização dos achados da pesquisa (Bertrand \& Bourdeau, 2010; Hanna, 2012). Esta forma de coleta de dados foi escolhida para evitar um contato pessoal entre pesquisadores e entrevistados, uma vez que entrevistas face a face poderiam deixar os participantes desconfortáveis e interferir na qualidade da informação coletada (Knapp \& Kirk, 2003).

De forma similar à primeira etapa, solicitou-se ao participante a autorização para gravar a entrevista. Então, perguntas gerais foram realizadas para quebrar o gelo e, em seguida, pediu-se aos participantes que descrevessem com a maior riqueza de detalhes possível uma situação de compra recente onde eles tivessem se sentido constrangidos. Um roteiro semiestruturado similar ao dos balconistas foi utilizado. Algumas perguntas deste roteiro foram: Onde você comprou? Qual era o tamanho da farmácia? Qual foi o horário? Como escolheu a farmácia e o horário? Por que você decidiu comprar este produto? Perguntas complementares inerentes às circunstâncias momentâneas foram empregadas.

Esse roteiro auxiliou também a levantar percepções em relação ao constrangimento, quando esse não foi comentado espontaneamente pelo consumidor, sendo pedido que o entrevistado descrevesse como se sentiu antes, durante e após a compra. Respostas condizentes com a literatura (Gerlach et al., 2003; Verbeke \& Bagozzi, 2002) corroboram que a emoção em questão foi o constrangimento, como as transcrições dos entrevistados descritas a seguir demonstram: "Parecia que a minha cara estava toda vermelha" (C13); "Ah, dá aquela (sensação) que a gente chama de borboletas no estômago, um frio na barriga" (C23); "Eu falei muito mais baixo que o normal" (C21); "Eu falei baixo, rápido e fiz uma expressão facial de pânico" (C07). 
Para verificar qual a percepção do consumidor em relação ao balconista, ao final da entrevista, foi perguntado se ele acredita que o atendente poderia identificar que estava constrangido, o que foi confirmado pela maioria dos entrevistados: "Eu tenho certeza que eu fiquei vermelha na hora, fingindo com cara de séria" (C21); "Eu finjo que está tudo bem, mas minha cara denuncia tudo. Então eu acho que o vendedor sabia" (C19); "Acho que quando eu peço, ele deve perceber sim, não é da forma natural" (C22).

É importante considerar que os pesquisadores desse estudo se preocuparam de diversas formas em minimizar um possível desconforto do entrevistado ao abordar o tema polêmico, como por exemplo: ao solicitar um local adequado na farmácia para realizar entrevistas, ao não usar uma entrevista face a face com consumidores e ao utilizar sempre questões iniciais de quebra-gelo. O uso dessas técnicas somado ao grande número de entrevistas realizadas com balconistas e consumidores (que se complementam) de diferentes regiões buscou garantir uma coleta de dados adequada, face ao método, para responder ao objetivo de pesquisa proposto nesse artigo. Além disso, optou-se por basear essa pesquisa em lembranças de situações em que o consumidor está constrangido, visto que as pessoas geralmente têm excelente memória de suas experiências quando uma emoção é o evento central dessa situação. Isso acontece, pois situações com emoções negativas produzem lembranças com maior riqueza de detalhes, uma vez que esta é uma forma do ser humano se proteger dessa situação, podendo no futuro evitar ou alterar os resultados de uma situação similar (uma revisão mais abrangente sobre o efeito das emoções negativas na memória pode ser encontrada em Levine \& Edelstein, 2009).

\section{Processo de Análise}

A apreciação dos dados foi feita por meio da análise de conteúdo, técnica que permite, pelo tratamento de transcrições de entrevistas, uma análise exploratória da situação apresentada (Vergara, 2008). Primeiramente, por meio de uma análise de todas as falas (atendentes e consumidores), foram verificados pontos comuns, repetições, construindo-se, assim, categorias de comportamentos e/ou situações.

As categorias foram criadas de acordo com um modelo aberto que, conforme Laville e Dionne (1999), é o modelo que não possui categorias fixas ou pré-estabelecidas. Ao invés disso, as categorias são formadas a partir do curso da análise. Desta forma, chegou-se a duas categorias principais, nomeadas de Abandonar a Situação e Lidar com a Situação. Em seguida, verificou-se ser possível separar o Lidar com a Situação em três subcategorias: Encorajar-se, Encarar e Fugir da Situação.

Com base na análise das descrições efetuadas por atendentes e consumidores, pode-se estruturar um framework conceitual do constrangimento no processo de compra juntamente com um conjunto de proposições de pesquisa. Desta forma, as categorias encontradas descrevem como é o processo de compra do consumidor quando ele está constrangido, respondendo à pergunta de pesquisa do presente artigo.

\section{Resultados}

Os resultados encontrados, baseados nas categorias criadas, são apresentados a seguir, juntamente com proposições teóricas que podem ser futuramente testadas. Trechos de falas dos atendentes da farmácia (A) e dos consumidores (C) foram utilizados para ilustrar os achados. 


\section{Abandonar ou lidar}

Os entrevistados confirmaram que o constrangimento é uma emoção negativa, incômoda, que faz com que eles se sintam desconfortáveis. Por isso, quando o constrangimento ocorre no ambiente de compra, surge o conflito entre se livrar imediatamente deste desconforto e lidar com a situação para completar o processo de compra. Exemplos deste conflito podem ser percebidos nas seguintes falas: "Vontade de cair fora dali, de sair correndo" (C10); "Não queria estar comprando aquilo, mas o medo (de ficar grávida) era maior". (C2).

De acordo com os entrevistados, o constrangimento pode surgir antes de ir à farmácia, ao pensar na necessidade do produto: "Eu estava em casa, tal, aí a minha noiva me mandou uma mensagem: ah, amor, passa na farmácia e compra para mim Modess... Fiquei com aquela cara" (C4), ou intensificar-se dentro da farmácia, por exemplo, ao ver o produto, ao interagir com o atendente ou quando a loja está cheia: "Eu me lembro claramente de ter que pedir perto de alguém e isso me constrangeu super" (C25).

Abandonar a compra ou lidar com a situação formam as primeiras categorias dessa análise. $\mathrm{O}$ ato de abandonar a compra consiste em não mais adquirir o produto ou ainda procurar outra solução para obter o mesmo. Por exemplo, as falas de atendentes e consumidores demonstraram que não é raro mulheres pedirem para seus parceiros comprarem pílula do dia seguinte, anticoncepcional e gel lubrificante: "Tem algumas mulheres que têm vergonha de comprar anticoncepcional. Aí ela fica aqui na perfumaria andando e o namorado é que vem para o balcão" (A7); "Eu não tive nem coragem de ir pedir o remédio. Pedi para o meu namorado fazer isso" (C01). No caso de lidar com a situação, o consumidor assume que precisa do produto e terá de enfrentar o sentimento: "Eu estava muito desesperada... minha preocupação era maior do que a minha vergonha de comprar" (C25).

Os resultados da análise sugerem que o comportamento de abandonar ou lidar com a situação são dois extremos de um contínuo, que são consequências do grau de constrangimento em que o consumidor se encontra. Em outras palavras, quanto mais constrangido o consumidor se sente, maior é a probabilidade dele abandonar a compra. A fala a seguir ilustra esta situação: "Era um atendente homem no caixa, aí desisti... fiquei com vergonha de ir lá na gôndola pegar as camisinhas. Pensei que iam ficar olhando" (C11). Assim:

Proposição 1 - Quanto maior for o grau de constrangimento do consumidor, maior é a probabilidade de ele abandonar a compra.

Esses achados são consistentes com estudos sobre a compra de preservativos, os quais sugerem que o constrangimento pode fazer com que consumidores desistam de realizar a compra, mas que os que a realizam desenvolvem estratégias para lidar com essa situação (Moore et al., 2006; Moore et al.,2008).

As entrevistas sugerem ainda que há outro fator que interfere na decisão entre abandonar ou lidar: a urgência de adquirir o produto. Urgência é definido como um sentimento de necessidade de iniciar e completar um ato imediatamente ou em um futuro próximo (Swain, Hanna, \& Abendroth, 2006). Quando um consumidor percebe a necessidade de adquirir um produto como urgente, maior é a probabilidade de ele realizar a compra (ou não desistir dela) (Swain et al., 2006; Verhoef \& Sloot, 2006).

Consistente com a literatura de urgência, a fala dos entrevistados sugere que quanto mais urgente for a compra, maior é chance de o consumidor lidar com o constrangimento, mesmo que este constrangimento seja forte. As falas a seguir ilustram esta relação: "Pensei em pegar, mas como só tinha um atendente, preferi nem pegar. Não era uma coisa que estivesse precisando muito" (C12); "Sei lá, hoje eu quero fazer um jantarzinho especial, daí eu acho que eu iria acabar encarando e pedindo, mas seria assim, quando eu estivesse realmente precisando. Não do tipo, vou só repor o estoque (de preservativo)" (C05).

Proposição 2 - A urgência do produto modera a relação entre o grau de constrangimento do consumidor e $\mathrm{o}$ ato de abandonar ou lidar, de forma que quanto maior a urgência, maior a chance de o consumidor lidar com essa compra. 


\section{Processo de compra}

A análise dos dados sugeriu que a categoria Lidar com a situação fosse dividida em três subcategorias de comportamento: Encorajar-se, Encarar e Fugir. A Figura 1 descreve este processo e suas respectivas subcategorias e itens. Importante comentar que o framework inicia-se com a emoção de constrangimento do consumidor, considerando que o artigo está focado em explorar o momento em que o consumidor está sentindo essa emoção relativa a uma situação de compra. Assim, não é objeto deste estudo explorar as causas ou antecedentes desse constrangimento ou a ação do consumidor no póscompra (utilização e descarte).

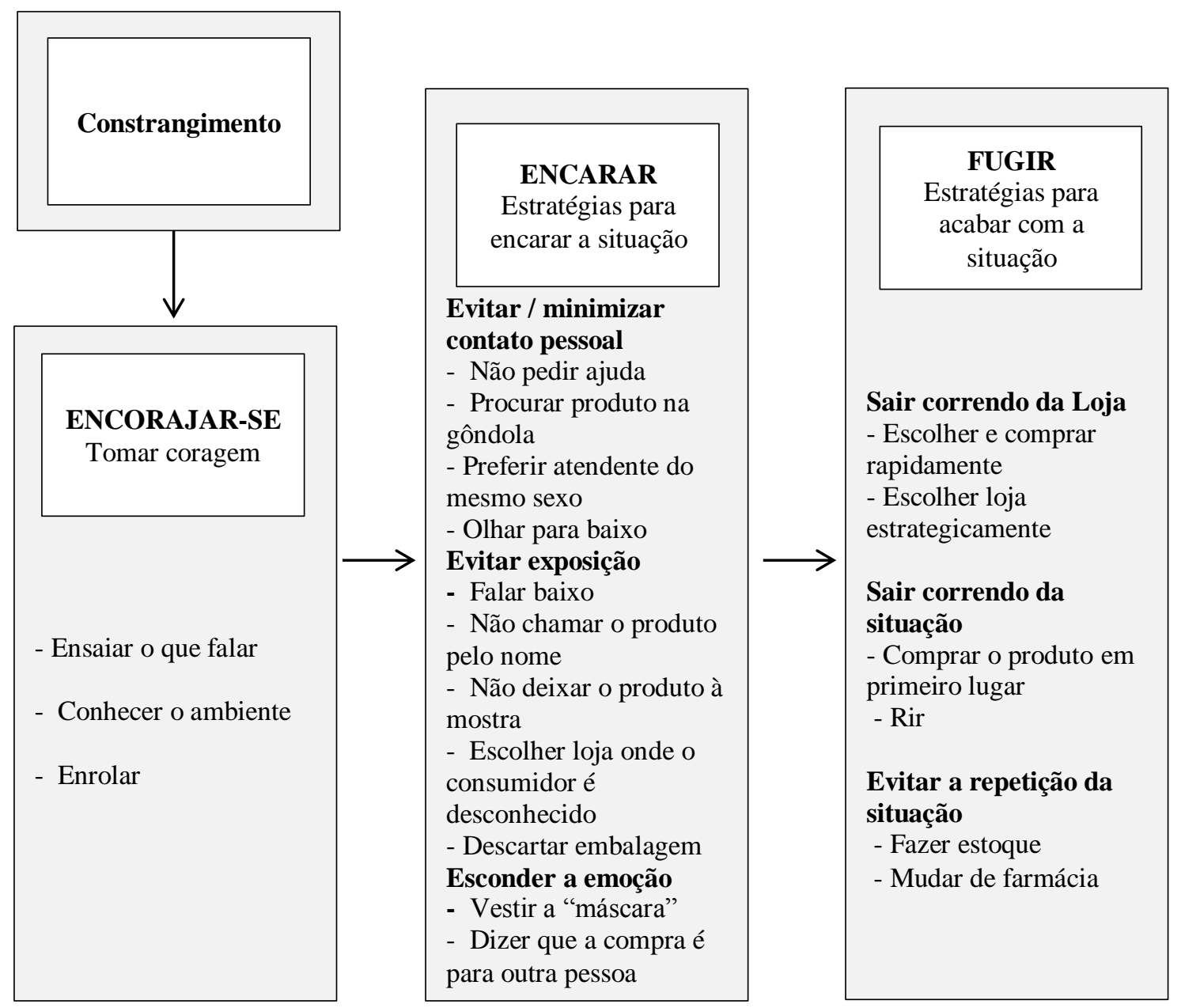

Figura 1. Framework do Processo de Compra Quando o Consumidor Está Constrangido

\section{Encarar}

A categoria Encarar consiste nas estratégias que o consumidor cria para enfrentar a situação de compra quando está constrangido. Essa categoria possui alguns comportamentos que foram classificados nas subcategorias nomeadas de evitar/minimizar o contato pessoal, evitar exposição e esconder a emoção. A Tabela 3 resume trechos de entrevistas dessa categoria. 
Tabela 3

\section{Trechos de Entrevistas sobre Situações de Encarar a Compra}

\begin{tabular}{ll}
\hline Categorias & Citações \\
\hline $\begin{array}{l}\text { Evitar ou minimizar o } \\
\text { contato pessoal }\end{array}$ & "É melhor ter menos contato humano possível." (C14) \\
\hline
\end{tabular}

Não pedir ajuda

"Um jovem ficou uns 15 minutos andando, recusou ajuda e quando saiu um rapaz, ele perguntou onde ficava o preservativo." (A22)

'Eu pensei: 'meu, que merda ter que pedir pro atendente'. Eu queria pegar e ir embora." (C25)

Procurar o produto na "Tem umas que ficam procurando (o preservativo) e não perguntam onde tá gôndola porque tá com vergonha." (A14)

"Você não tem muito o que perguntar. Você não precisa de receita, você não precisa de nada, então porque que eu tenho que pedir para alguém?” (C25)

Olhar para baixo

"Falam baixo, não olham no nosso rosto, muitas vezes falam conosco e no celular ao mesmo tempo." (A02)

"Porque não conseguia nem olhar pra mulher." (C16)

Preferir atendente do mesmo sexo

"Geralmente quando ele não sabe onde fica, ele fica esperando alguém atender ele, que seja homem. Geralmente a gente atende e eles falam que não precisam de ajuda. Aí quando chega um rapaz e pergunta, aí eles falam.” (A21)

"Hoje só frequento a Drogasil, que é perto de casa e que sei que tem mulheres para essa prestação de serviços.” (C15)

\section{Evitar exposição}

"E eu não quero que ninguém saiba da minha vida, entendeu? Ou que julgue alguma coisa do que eu tô fazendo. Essa era a minha principal preocupação.” (C25)

"Ficar escolhendo seria como ficar demonstrando publicamente algo íntimo." (C12)

Falar baixo

"Elas chegam de canto, pedem para balconista mulher. Falam baixinho." (A11)

"Eu acho que ele deve ter percebido. Por que eu tentei falar mais baixinho, sabe?" (C25)

Não chamar o produto pelo "No caso do homem, a maioria utiliza o nosso código. Nós temos um código Vx2 nome (Viagra caixa com 2), Vx4 (caixa com 4) Cl 2 (Cialis com 2)." (A20)

"No nível de bobeira que estava, falar 'pílula do dia seguinte' seria complicado." (C26)

Não deixar o produto à mostra

"Coloca outro produto em cima. Aí na hora de passar no caixa, quando a gente pega a cestinha, aí a gente vai tirando os produtos e aí a gente vê que embaixo tem um preservativo, um lubrificante, alguma coisa assim." (A12)

"A camisinha, eu ainda tenho um pouco de vergonha, acabo levando outra coisa junto para disfarçar. Xampu, sabonete líquido, algum produto de beleza." (C01)

Escolher loja onde o

"Mas não tive coragem de comprar na farmácia do bairro, fui no shopping Rio consumidor é desconhecido

Sul comprar, acredita? E olha que morava em Santa Teresa." (C26)

"Eu pensei: essa é a farmácia, pois eu nunca mais volto aqui também.” (C21)

\section{Esconder a emoção}

"Coloco na cestinha e entrego para ela e fico olhando para ela como se nada tivesse acontecido." (C23)

"Para mim, ir nessa gôndola era um stress, era pegar e sair correndo, e fingir que eu não estava comprando nada demais." (C21) 


\section{Tabela 3 (continuação)}

\begin{tabular}{|c|c|}
\hline Categorias & Citações \\
\hline \multirow[t]{2}{*}{ Vestir a máscara } & "Então eu visto a cara de pau e compro." (C23) \\
\hline & $\begin{array}{l}\text { "Assim, eu vou na caruda, geralmente eu compro mais alguma coisa, assim, para } \\
\text { ajudar, sabe?" (C23) }\end{array}$ \\
\hline \multirow[t]{2}{*}{$\begin{array}{l}\text { Dizer que a compra é para } \\
\text { outra pessoa }\end{array}$} & $\begin{array}{l}\text { "Sempre tem um rapaz que compra pro tio e está sempre no celular: Qual é } \\
\text { mesmo o nome do remédio, tio?" (A17) }\end{array}$ \\
\hline & $\begin{array}{l}\text { "Muitas vezes um rapaz tá comprando e fala: 'tem um Viagra? Vou comprar pro } \\
\text { meu pai, pro meu vô'." (A04) }\end{array}$ \\
\hline
\end{tabular}

Nota. A - atendente e $\mathrm{C}$ - consumidor.

Como a exposição em público pode causar constrangimento, o consumidor evita uma interação social, preferindo realizar suas compras no autosserviço. No caso de produtos constrangedores que podem ser encontrados em gôndolas, o consumidor aparentemente tenta não pedir ajuda. Se necessário perguntar ao atendente, o consumidor prefere abordar balconistas do mesmo sexo, principalmente no caso de produtos exclusivamente masculinos ou femininos. Por exemplo, homens preferem comprar Viagra com homens, e mulheres preferem comprar teste de gravidez com mulheres. Entretanto, uma exceção bastante mencionada foi o caso de absorventes, em que a funcionária mulher foi vista como especialista, sendo preferida por consumidores de ambos os sexos.

Nessa subcategoria, as falas dos entrevistados sugerem que ser atendido por funcionários do mesmo sexo traz uma sensação de conforto e segurança, o que facilita o enfrentamento do constrangimento e, consequentemente, a realização da compra. "Quando o assunto é algo ginecológico, eu ficaria mais confortável sendo atendida por uma mulher" (C13); "Não sei se passou algo na mente do atendente, mas é bem provável, pois ele teve um olhar curioso. Se fosse uma mulher, acredito que não teria esse olhar, pois ela entenderia logo que era para outra mulher" (C09). Desta forma, consistente com achados anteriores para a compra de preservativos (Moore et al., 2006; Moore et al., 2008), mais uma proposição é apresentada.

Proposição 3 - Interações sociais entre pessoas do mesmo sexo, em momentos onde o consumidor está constrangido, fornecem uma sensação de maior conforto.

Na subcategoria de evitar exposição, ao pedir o produto, os consumidores falam baixo e evitam chamá-lo pelo nome. Para isso, criam apelidos e códigos para conversar com o balconista, como azulzinho e Vx4, no caso do Viagra, ou aquela pílula lá, no caso da pílula do dia seguinte. Consumidores inclusive comentaram procurar o nome científico do produto a ser comprado, na Internet, para que possam utilizar uma nomenclatura que apenas o balconista possa entender.

Outra estratégia utilizada pelos consumidores, que tem o objetivo de evitar exposição, é escolher uma farmácia onde o consumidor não seja conhecido, ou seja, onde o atendente não seja seu amigo ou a chance de se encontrar alguém conhecido seja pequena. Nesse ponto, alguns consumidores procuraram farmácias maiores ou longe de suas casas.

Quando o produto está na gôndola, evitar exposição pode significar a compra de outra mercadoria para disfarçar. Foram mencionados, por exemplo, consumidores que compraram produtos com embalagens maiores para cobrir preservativo nas cestas de compras, como caixas de lenços ou shampoo. Em geral, esses produtos cuja compra não foi planejada são produtos de consumo imediato ou de rápida utilização.

Desta forma, a localização do produto constrangedor na gôndola ou no balcão parece interferir no comportamento de compra. Observou-se nas falas que quando o produto é retirado da gôndola pelo consumidor, ele evita deixá-lo à mostra, muitas vezes, adquirindo um produto sem necessidade imediata para encobrir ou disfarçar sua compra. 
Entretanto, quando o produto é vendido apenas no balcão, o consumidor obrigatoriamente precisa passar por uma ou mais interações pessoais. Ainda assim, ele evita o contato pessoal, olhando para baixo ou desviando o olhar. Esta interação faz com que ele queira sair desta situação o mais breve possível e, por isso, adquire apenas um produto, indo direto para o caixa.

Em ambas as situações, percebe-se que o constrangimento gera uma necessidade de se livrar desta emoção o mais rápido possível, consistente com Verbeke e Bagozzi (2002). Isso gera consequências interessantes no processo de compra, dependendo da localização do produto. Quando o produto está na gôndola, a maneira mais rápida de reduzir a exposição é incluir outros produtos na cesta de compras, enquanto no balcão, é correr até o caixa.

Proposição 4 - O número de itens da cesta de compras de um consumidor constrangido está relacionado à necessidade de interagir diretamente com o atendente.

A subcategoria Escondendo a Emoção consiste no grupo de consumidores que tentam disfarçar que estão constrangidos, para que ninguém perceba. Eles mencionam que vestem a cara de pau ou vão na caruda (cara dura) e compram o produto como se não estivessem sentindo esta emoção, como se estivessem comprando um produto qualquer. Esses consumidores comentam que utilizam algumas estratégias, como olhar fixamente nos olhos dos balconistas ou pedir o produto de forma fina e educada. Ainda nesse item, encontram-se os consumidores que chegam ao balcão comentando que o produto é para outra pessoa.

\section{Fugir}

Os consumidores, após tomarem coragem, encaram as situações de constrangimento. Entretanto, durante o processo de compra, essa emoção negativa ainda está presente, por isso, o objetivo principal dessas pessoas é se livrar dessa emoção. Dentro da categoria Fugir, há três grupos de comportamento: aqueles que agem para sair correndo da loja, os que agem para se livrar da situação e aqueles que criam estratégias para não passar por essas situações no futuro.

$\mathrm{Na}$ subcategoria Sair Correndo da Loja, as falas dos entrevistados sugerem que, para isso, a compra em geral é rápida ("Você percebe, assim, na rapidez da pessoa que pega e vai correndo pro caixa e já vai embora rápido." (A12); "Fui para o caixa e disse: Débito! Ela me perguntou se eu queria CPF na nota e eu disse não, pois queria sair daquela situação o mais rápido possível" (C07)). Desta forma, ao sair correndo, entende-se que o consumidor consegue se livrar do sentimento constrangedor, uma vez que ele deixa de sentir-se exposto (Lewis \& Ramsay, 2002).

Proposição 5 - O constrangimento aumenta a velocidade em que o consumidor passa pelo processo de compra, pois ele precisa se livrar deste sentimento.

Aumentar a velocidade da compra muitas vezes significa aumentar a velocidade de escolha, uma vez que são ofertados diferentes marcas e tipos dos produtos que possam suprir a necessidade do consumidor. Para minimizar esse tempo, o consumidor utiliza atalhos na tomada de decisão, tornandoa mais heurística (Chaiken \& Maheswaran, 1994). Neste caso, o constrangimento serve como um limitador de recursos de processamento de informação, uma vez que tanto expressar quanto suprimir emoções resultam num aumento de carga cognitiva (Bonanno, Papa, Lalande, Westphal, \& Coifman, 2004). As entrevistas demonstraram que esses atalhos incluem escolher marcas fortes, aceitar a indicação do balconista e não levar o preço em consideração, como apresentado nas falas a seguir: "Nada que demorasse mais do que poucos 3 segundos. Eu escolhia assim, embalagem e marca. A marca que eu já tinha ouvido falar, e a embalagem mais bonitinha caso eu não tivesse ouvido falar." (C21); "Ele me entregou vários, colocou vários em cima do balcão. Ele me explicou qual era a diferença, que um era mais caro porque era mais confiável... Eu comprei o que ele disse que era o mais confiável. (C22)"; "Não lembro (de perguntar o preço). Mas no fundo não importava, porque eu não iria entrar em outra farmácia" (C26). 
Proposição 6 - O constrangimento aumenta o uso de atalhos na tomada de decisão, tornando-a mais heurística, pois ele limita recursos de processamento de informação.

Enquanto alguns consumidores entrevistados compravam o produto que causava constrangimento pela primeira vez, outros já haviam passado pela situação anteriormente. Essa diferença na familiaridade da situação foi refletida no comportamento descrito pelos entrevistados e é consistente aos achados de Moore et al. (2006) e Moore et al., (2008) na compra de preservativos. Observou-se que quando o consumidor acumula experiência na compra do produto, ele adquire conhecimento que possibilita uma decisão mais sistemática, enfraquecendo a relação entre o constrangimento e os atalhos anteriormente citados. Algumas falas dos consumidores e atendentes exemplificam essa situação: "Eu não tinha conhecimento de comprar o produto (pílula do dia seguinte) então eu não sei se eu teria capacidade de comprar sozinha, mas se eu conseguisse escolher sozinha, com certeza seria mais fácil." (C21); "Eu escolho o produto, eu vou na seção, vou ali, e já sei qual a marca que eu gosto. Eu pego, sim, eu escolho" (C23).

Proposição 7 - O conhecimento do produto enfraquece a relação entre o constrangimento e o uso de atalhos na tomada de decisão, tornando-a mais sistemática.

Muitos consumidores, sabendo que terão de encarar a compra, buscam um auto planejamento não só em como atuar dentro da farmácia, mas também em qual farmácia ir. Por exemplo, escolhem farmácias onde já sabem que o produto fica em gôndolas ou onde ele está localizado. O objetivo é tornar o processo o mais rápido possível para conseguir sair da loja.

Além de sair correndo, muitas vezes os consumidores têm estratégias para sair rapidamente da situação de constrangimento ainda dentro da loja. Essas estratégias foram subcategorizadas como Fugir da Situação. Entre essas estratégias, as mais comuns na fala dos entrevistados foram: comprar o produto em primeiro lugar, para se livrar logo da situação; e rir, durante a interação com o balconista ou outras pessoas. Nesta última, ao invés de esconder o constrangimento, o consumidor decide assumi-lo, tirando sarro da situação, ou seja, usando o humor para lidar com o desconforto que está sentindo.

O consumidor age para evitar passar pelo mesmo tipo de situação no futuro. Neste sentido, foram encontradas duas ações distintas: comprar o produto em grande quantidade, para fazer um estoque, ou trocar de farmácia, para não precisar interagir com as mesmas pessoas no futuro. Para finalizar essa categoria, resumem-se algumas falas na Tabela 4.

Tabela 4

\section{Trechos de Entrevistas sobre Situações de Fugir}

\begin{tabular}{|c|c|}
\hline Categorias & Citações \\
\hline \multirow[t]{2}{*}{ Fugir (Sair correndo da loja) } & $\begin{array}{l}\text { "Queria sair correndo de lá. Paguei, coloquei o teste na bolsa e saí de lá o } \\
\text { mais rápido possível." (C21) }\end{array}$ \\
\hline & "Saí dali rapidinho." (C15) \\
\hline \multirow[t]{2}{*}{ Escolher e comprar rapidamente } & $\begin{array}{l}\text { "E tem cliente que você vê que já nem olha na sua cara e já tá lá no meio da } \\
\text { rua, não espera nem você imprimir a nota." (A03) }\end{array}$ \\
\hline & $\begin{array}{l}\text { "Acho até que ela falou que teria outras opções, mas eu cortei. Eu só queria } \\
\text { pegar e sair." (C26) }\end{array}$ \\
\hline \multirow[t]{2}{*}{ Escolher loja estrategicamente } & $\begin{array}{l}\text { "Nas farmácias populares os atendentes olham a minha receita de } \\
\text { medicamentos como se fosse de antiinflamatório." (C06) }\end{array}$ \\
\hline & $\begin{array}{l}\text { "Eu prefiro ir na farmácia grande, pois acho que é mais popular, mais } \\
\text { democrático, sei lá, acho que é menos constrangedor." (C13) }\end{array}$ \\
\hline
\end{tabular}




\section{Tabela 4 (continuação)}

\begin{tabular}{|c|c|}
\hline \multicolumn{2}{|l|}{ Sair correndo da situação } \\
\hline \multirow[t]{2}{*}{$\begin{array}{l}\text { Comprar o produto em primeiro } \\
\text { lugar }\end{array}$} & $\begin{array}{l}\text { "Eu tinha de pegar muitas outras coisas, primeiro eu queria pegar isso para } \\
\text { me safar, e só depois pedi o resto, pois eu tinha receita do resto. Primeiro eu } \\
\text { pedi a periometrina e depois eu fui atrás das outras coisas." (C18) }\end{array}$ \\
\hline & $\begin{array}{l}\text { "Eu, além disso, acho que comprei um pacote de bala, mas não me lembro, } \\
\text { era alguma coisa que eu poderia consumir fácil - era algo que não fazia } \\
\text { muita importância para mim, era só para disfarçar." (C07) }\end{array}$ \\
\hline \multirow[t]{2}{*}{ Rir } & $\begin{array}{l}\text { "Eu já tiro sarro da situação, entendeu? A pessoa acaba rindo, né? Nesse } \\
\text { ponto eu não faço tempestade em copo de água não, eu entro na } \\
\text { brincadeira." (C04) }\end{array}$ \\
\hline & $\begin{array}{l}\text { "Uma senhora que estava na farmácia ficou me olhando e perguntou se eu } \\
\text { sempre comprava! Eu, sem perceber, respondi: Não, é a primeira vez. E } \\
\text { rimos." (C09) }\end{array}$ \\
\hline \multicolumn{2}{|l|}{ Evitar a repetição da situação } \\
\hline \multirow[t]{2}{*}{ Fazer estoque } & $\begin{array}{l}\text { "Muitas vezes a gente compra em grande quantidade, para não precisar ir } \\
\text { novamente." (C07) }\end{array}$ \\
\hline & $\begin{array}{l}\text { “O dia que eu for tentar ficar grávida e eu precisar obviamente fazer esses } \\
\text { exames, eu provavelmente vou ter a atitude de comprar umas } 5 \text { caixas. É } \\
\text { sério, porque tipo, eu não vou querer voltar todo mês na farmácia. Para a } \\
\text { pessoa não pensar 'ah, coitada, ela não engravidou de novo', sabe, 'ah, ela tá } \\
\text { vindo aqui comprar de novo'." (C25) }\end{array}$ \\
\hline \multirow[t]{2}{*}{ Mudar de farmácia } & $\begin{array}{l}\text { "Foi a última vez que eu fui lá também, nunca mais voltei naquele lugar." } \\
\text { (C14) }\end{array}$ \\
\hline & “Mas não volto naquela farmácia.” (C24) \\
\hline
\end{tabular}

Nota. A - atendente e $\mathrm{C}$ - consumidor.

\section{Constrangimento e vergonha na farmácia}

Quando perguntada sobre quais outras emoções as pessoas sentiram ao entrarem na loja para comprar um produto, algumas pessoas comentaram sentir-se envergonhadas. Entretanto, percebe-se pela fala que a palavra vergonha tem sentido de constrangimento. Por exemplo: "Rola uma vergonhinha, mas tranquilo. É só uma vergonha de momento que depois que já tô pagando, já passa e pronto." (C17); "A gente está falando de uma pequena vergonha, um pequeno constrangimento, de bobagens que passam na nossa cabeça, de pessoas que estão julgando a gente, que os outros vão saber que você vai fazer sexo, esse tipo de coisas". (C13)

\section{Discussão dos Resultados}

Os resultados da pesquisa mostraram que o constrangimento influencia o processo de compra de diversas formas, estendendo e enriquecendo a literatura de constrangimento no comportamento do consumidor. Além dos aspectos descritivos, os resultados sugerem alguns mecanismos causais para explicar por que o consumidor se comporta de determinada forma quando está constrangido.

Ao relacionar o grau de constrangimento do consumidor à probabilidade de ele abandonar a compra, o artigo expande os achados de Brumbaugh e Rosa (2009) (de que os consumidores deixam de usar cupons para evitar se sentirem constrangidos) para outras categorias de produtos (por exemplo, preservativos e espermicidas) e situações de compra. Os resultados acrescentam ainda o papel da 
urgência em adquirir o produto como moderador da relação entre o grau de constrangimento do consumidor e a decisão de abandonar ou lidar.

Segundo Mowen (1988), quando o consumidor tem a necessidade de solucionar um problema, ele se engaja na avaliação cognitiva dos benefícios tangíveis do produto. Os resultados deste artigo mostram que o constrangimento atrapalha o processamento de informação sistemático, necessitando passar por uma fase de encorajamento. Assim, este encorajamento surge como mecanismo causal que aumenta a chance de o consumidor encarar a compra, porque ele passa a dar mais peso aos aspectos racionais do que aos emocionais da tomada de decisão.

Uma vez que o constrangimento é uma emoção desconfortável e perturbadora (Miller, 2001), outro mecanismo causal apresentado é a sensação de conforto. Ela explica a relação entre o constrangimento e a busca de atendentes do mesmo sexo. Além disso, para minimizar o desconforto de se sentir exposto (Lewis et al., 1991), o consumidor busca livrar-se do constrangimento o mais rápido possível (Verbeke \& Bagozzi, 2002). Por isso, ele compra mais itens quando o produto está na gôndola e menos itens quando o produto é vendido no balcão.

Finalmente, o fato de o constrangimento aumentar a velocidade em que o consumidor passa pelo processo de compra pode ser explicado por um aumento no uso de atalhos na tomada de decisão, tornando-a mais heurística. É interessante comentar que apesar de as decisões heurísticas geralmente resultarem do impacto de emoções positivas (Isen \& Means, 1983) e de produtos hedônicos (Mowen 1988), os resultados sugerem que a emoção negativa do constrangimento em compra de produtos considerados mais utilitários também gera esta forma de processamento.

Esses resultados estendem os achados de Shiv e Fedorikhin (1999), indicando que a tomada de decisão heurística acontece, pois o constrangimento limita recursos de processamento de informação. Além disso, eles reforçam os achados de Lench, Flores e Bench (2011), que explicam que emoções de mesma valência podem levar a comportamentos distintos.

Por fim, observa-se uma situação que enfraquece essa relação entre o constrangimento e o uso de atalhos na tomada de decisão, que é o conhecimento do produto. Assim, quando o consumidor já tem informações adicionais sobre o produto a ser comprado, não há necessidade de tantos recursos de processamento de informação, tornando a decisão mais sistemática.

\section{Considerações Finais}

A literatura do constrangimento no comportamento do consumidor aborda situações de compra e consumo que antecedem o constrangimento (Blair \& Roese, 2013; Brumbaugh \& Rosa, 2009; Dahl et al., 2001; Picca \& Joos, 2009), situações em que o consumidor age para evitar experimentar esta emoção no futuro (Bell, 2009; Grace, 2007; Miller, 2001) e como o consumidor se comporta no momento em que está constrangido (Brackett, 2004; Ekebas \& Arndt, 2015; Picca \& Joos, 2009).

O presente estudo encontra-se no terceiro tema, preenchendo a lacuna de mostrar de forma integrada como o consumidor se comporta quando está constrangido. Com uma pesquisa empírica, foi possível mapear como o consumidor se comporta, resultando num processo de compras distinto do usual. Dentro dele, foram apresentadas sete proposições que avançam no conhecimento sobre a influência do constrangimento no comportamento de compra.

O resultado da pesquisa empírica sugere algumas implicações importantes, que podem facilitar o processo de compra em situações de constrangimento. A primeira delas é a velocidade: o consumidor quer resolver seu problema da forma mais rápida possível. Por isso, ações que facilitem o processo de compra, como deixar os produtos em locais fáceis de encontrar, diminuir filas no atendimento e no caixa, dar destaque a marcas mais conhecidas e ter um menor sortimento para facilitar a escolha, são valorizadas por este consumidor. 
Outra implicação é o contato pessoal: quanto menor, melhor. Uma vez que a interação social pode aumentar a sensação de constrangimento (Grace, 2007; Lewis \& Ramsay, 2002), comprar um produto no autosserviço pode ser uma alternativa para o consumidor, evitando sua exposição direta a um balconista. Isso possui implicações gerenciais, já que é possível que produtos que não precisem ficar atrás do balcão, como preservativos e testes de gravidez, tenham suas vendas aumentadas no autosserviço, por serem produtos constrangedores.

Como nem todos os produtos podem ficar nas gôndolas e o consumidor constrangido sente-se exposto ao ter que pedir o produto no balcão, ter funcionários treinados para agir com discrição e rapidez parece importante para conquistar este consumidor. Por isso, dar a opção de escolher um balconista do mesmo sexo pode deixá-lo mais à vontade.

Nas gôndolas, uma vez que é comum o consumidor comprar produtos dispostos próximos aos produtos constrangedores, os varejistas poderão utilizar-se dessa informação para aumentar as vendas de produtos de alto giro, principalmente os de embalagens grandes.

Por fim, a velocidade da compra implica em menos tempo para comparar preços e barganhar descontos. Isso sugere que preço não é um fator decisivo na compra de produtos constrangedores, principalmente quando o consumidor tem pouca experiência com sua compra.

Esta pesquisa possui algumas limitações. Por exemplo, o recrutamento de respondentes pelo método bola de neve pode ter excluído consumidores extremamente constrangidos, que podem ter escolhido não participar das entrevistas, cujos relatos poderiam enriquecer os achados desta pesquisa. Além disso, a análise dos dados resultou em sete proposições que sugerem relações causais, mas não eliminam explicações alternativas. Pesquisas futuras podem testar essas relações por meio de surveys ou experimentos.

\section{Agradecimentos}

Os autores agradecem à todos os entrevistados dessa pesquisa (atendentes, balconistas, gerentes e consumidores). Reconhecese também a CAPES pelos recursos recebidos por meio da bolsa de doutorado as pesquisadoras (Processo $\mathrm{n}^{\circ} 1243987$ ) e ao CNPQ e FAPESP pelo suporte financeiro à pesquisa.

\section{Referências}

Bell, J. (2009). Why embarrassment inhibits the acquisition and use of condoms: a qualitative approach to understanding risky sexual behaviour. Journal of Adolescence, 32(2), 379-391. doi: 10.1016/j.adolescence.2008.01.002

Bertrand, C., \& Bourdeau, L. (2010, June). Research interviews by skype: a new data collection method. Proceedings of the European Conference on Research Methodology for Business and Management Studies, Madrid, Spain, 9.

Blair, S., \& Roese, N. J. (2013). Balancing the basket: the role of shopping basket composition in embarrassment. Journal of Consumer Research, 40(4), 676-691. doi: http://dx.doi.org/10.1086/671761

Bonanno, G. A., Papa, A., Lalande, K., Westphal, M., \& Coifman, K. (2004). The importance of being flexible the ability to both enhance and suppress emotional expression predicts long-term adjustment. Psychological Science, 15(7), 482-487. doi: 10.1111/j.0956-7976.2004.00705.x 
Brackett, K. P. (2004). College students' condom purchase strategies. The Social Science Journal, 41(3), 459-464. doi: 10.1016/j.soscij.2004.04.006

Brumbaugh, A. M., \& Rosa, J. A. (2009). Perceived discrimination, cashier metaperceptions, embarrassment, and confidence as influencers of coupon use: an ethnoracial-socioeconomic analysis. Journal of Retailing, 85(3), 347-362. doi: 10.1016/j.jretai.2009.04.008

Chaiken, S., \& Maheswaran, D. (1994). Heuristic processing can bias systematic processing: effects of source credibility, argument ambiguity, and task importance on attitude judgment. Journal of Personality and Social Psychology, 66(3), 460-473. doi: 10.1037/0022-3514.66.3.460

Dahl, D., Manchanda, R. V., \& Argo, J. J. (2001). Embarrassment in consumer purchase: the roles of social presence and purchase familiarity. Journal of Consumer Research, 28(3), 473-481. doi: $10.1086 / 323734$

Duhachek, A., Agrawal, N., \& Han, D. (2012). Guilt versus shame: coping, fluency, and framing in the effectiveness of responsible drinking messages. Journal of Marketing Research, 49(6), 928-941. doi: $10.1509 /$ jmr. 10.0244

Ekebas, C., \& Arndt, A. (2015). "I am so embarrassed!” How personal and empathic embarrassment in personal product purchasing impacts sales clerk choice. In L. Robison Jr. (Ed.), Marketing dynamism \& sustainability: things change, things stay the same... (p. 175). Ruston, LA: Springer International Publishing

Elsbach, K. D., \& Barr, P. S. (1999). The effects of mood on individuals' use of structured decision protocols. Organization Science, 10(2), 181-198. doi: 10.1287/orsc.10.2.181

Feinberg, M., Willer, R., \& Keltner, D. (2012). Flustered and faithful: embarrassment as a signal of prosociality. Journal of Personality and Social Psychology, 102(1), 81-97. doi: $10.1037 / \mathrm{a} 0025403$

Fenner, Y., Garland, S. M., Moore, E. E., Jayasinghe, Y., Fletcher, A., Tabrizi, S. N., \& Wark, J. D. (2012). Web-based recruiting for health research using a social networking site: an exploratory study. Journal of Medical Internet Research, 14(1), e20. doi: 10.2196/jmir.1978

Ferreira, V. R. (2011) Anotações em torno do feminino em Lispector: polifonia na tarefa do tradutor. Vertentes, 19(1), 80-94.

Gerlach, A., Roth, W., \& Frank, W. (2003). Embarrassment and social phobia: the role of parasympathetic activation. Anxiety Disorders, 17(2), 197-210. doi: 10.1016/S08876185(02)00197-4

Grace, D. (2007). How embarrassing! An exploratory study of critical incidents including affective reactions. Journal of Service Research, 9(3), 271-284. doi: 10.1177/109467050700900305

Grace, D. (2009). An examination of consumer embarrassment and repatronage intentions in the context of emotional service encounters. Journal of Retailing and Consumer Services, 16(1), 1-9. doi: 10.1016/j.jretconser.2008.02.004

Hanna, P. (2012). Using internet technologies (such as Skype) as a research medium: a research note. Qualitative Research, 12(2), 239-242. doi: 10.1177/1468794111426607

Heller, A. (2003). Five approaches to the phenomenon of shame. Social Research, 70(4), 1015-1030.

Higuchi, M., \& Fukada, H. (2002). A comparison of four causal factors of embarrassment in public and private situations. The Journal of Psychology, 136(4), 399-406. doi: $10.1080 / 00223980209604166$ 
Isen, A. M., \& Means, B. (1983). The influence of positive affect on decision-making strategy. Social Cognition, 2(1), 18-31. doi: 10.1521/soco.1983.2.1.18

Izard, C. E. (1977). Human emotions. New York: Plenum Press.

Keltner, D. (1996). Evidence for the distinctness of embarrassment, shame, and guilt: a study of recalled antecedents and facial expressions of emotion. Cognition \& Emotion, 10(2), 155-172. doi: $10.1080 / 026999396380312$

Keltner, D., \& Buswell, B. N. (1997). Embarrassment: its distinct form and appeasement functions. Psychological Bulletin, 122(3), 250-270. doi: 10.1037//0033-2909.122.3.250

Knapp, H., \& Kirk, S. A. (2003). Using pencil and paper, internet and touch-tone phones for selfadministered surveys: does methodology matter? Computers in Human Behavior, 19(1), 117-134. doi: 10.1016/S0747-5632(02)00008-0

Laros, F. J. M., \& Steenkamp, J.-B. E. M. (2005). Emotions in consumer behavior: a hierarchical approach. Journal of Business Research, 58(10), 1437-1445. doi: 10.1016/j.jbusres.2003.09.013

La Taille, Y. de (2002). Sentimento de vergonha e suas relações com a moralidade. Psicologia: Reflexão e Crítica, 15(1), 13-25. doi: 10.1590/S0102-79722002000100003

Lau-Gesk, L., \& Drolet, A. (2008). The publicly self-consciousness consumer: prepared to be embarrassed. Journal of Consumer Psychology, 18(2), 127-136. doi: 10.1016/j.jcps.2008.01.007

Laville, C., \& Dionne, J. (1999). A construção do saber: manual de metodologia da pesquisa em ciências humanas. Belo Horizonte: Artmed; UFMG.

Lench, H. C., Flores, S. A., \& Bench, S. W. (2011). Discrete emotions predict changes in cognition, judgment, experience, behavior, and physiology: a meta-analysis of experimental emotion elicitations. Psychological Bulletin, 137(5), 834-855. doi: 10.1037/a0024244

Levine, L. J., \& Edelstein, R. S. (2009). Emotion and memory narrowing: a review and goal-relevance approach. Cognition and Emotion, 23(5), 833-875. doi: 10.1080/02699930902738863

Lewis, M., \& Ramsay, D. (2002). Cortisol response to embarrassment and shame. Child Development, 73(4), 1034-1045. doi: 10.1111/1467-8624.00455

Lewis, M., Stanger, C., Sullivan, M. W., \& Barone, P. (1991). Changes in embarrassment as a function of age, sex and situation. British Journal of Developmental Psychology, 9, 485-492. doi: 10.1111/j.2044-835X.1991.tb00891.x

Lupton, D. (1994). The condom in the age of AIDS: newly respectable or still a dirty word? A discourse analysis. Qualitative Health Research, 4(3), 304-320. doi: 10.1177/104973239400400304

Miller, R. S. (2001). On the primacy of embarrassment in social life. Psychological Inquiry, 12(1), 3033.

Moore, S. G., Dahl, D. W., Gorn, G. J., \& Weinberg, C. B. (2006). Coping with condom embarrassment. Psychology, Health \& Medicine, 11(1), 70-79. doi: 10.1080/13548500500093696

Moore, S. G., Dahl, D. W., Gorn, G. J., Weinberg, C. B., Park, J., \& Jiang, Y. (2008). Condom embarrassment: coping and consequences for condom use in three countries. AIDS Care, 20(5), 553-559. doi: 10.1080/09540120701867214

Mowen, J. C. (1988). Beyond consumer decision making. Journal of Consumer Marketing, 5(1), 15-25. doi: 10.1108/eb008214 
Nichols, B. S. R., Raska, D., \& Flint, D. J. (2012). Product masking: effects of consumer embarrassment on shopping basket size and value. In T. J. Arnold \& L. K. Scheer (Eds.), Marketing in the socially-networked world: challenges of emerging, stagnant, and resurgent markets (pp. 311312). Chicago, IL: American Marketing Association.

Picca, L. H., \& Joos, K. E. (2009). The great condom adventure: analyzing college students' narratives of buying condoms. Journal of Sociological Research, 1(1), 1-16. doi: 10.5296/jsr.v1i1.201

Ramo, D. E., \& Prochaska, J. J. (2012). Broad reach and targeted recruitment using Facebook for an online survey of young adult substance use. Journal of Medical Internet Research, 14(1), e28. doi: 10.2196/jmir.1878

Rucker, D. D., \& Petty, R. E. (2004). Emotion specificity and consumer behavior: anger, sadness, and preference for activity. Motivation and Emotion, 28(1), 3-21. doi: 10.1023/B:MOEM.0000027275.95071.82

Russell, J. A. (1980). A circumplex model of affect. Journal of Personality and Social Psychology, 39(6), 1161-1178. doi: 10.1037/h0077714

Sabini, J., Garvey, B., \& Hall, A. L. (2001). Shame and embarrassment revisited. Personality and Social Psychology Bulletin, 27(1), 104-117. doi: 10.1177/0146167201271009

Sauerbronn, J. F. R., Ayrosa, E. A. T., \& Barros, D. F. (2009). Bases sociais das emoções do consumidor: uma abordagem complementar sobre emoções e consumo. Cadernos EBAPE. BR, 7(1), 169-182. Recuperado de http://www.scielo.br/pdf/cebape/v7n1/v7n1a12.pdf. doi: 10.1590/S167939512009000100012

Shiv, B., \& Fedorikhin, A. (1999). Heart and mind in conflict: the interplay of affect and cognition in consumer decision making. Journal of Consumer Research, 26(3), 278-292. doi: 10.1086/209563

Smith, C. A., \& Ellsworth, P. C. (1985). Patterns of cognitive appraisal in emotion. Journal of Personality and Social Psychology, 48(4), 813-838. doi: 10.1037/0022-3514.48.4.813

Swain, S. D., Hanna, R., \& Abendroth, L. J. (2006). How time restrictions work: the roles of urgency, anticipated regret, and deal evaluations. Advances in Consumer Research, 33(1), 523-525.

Tanner, J. F., Jr., Hunt, J. B., \& Eppright, D. R. (1991). The protection motivation model: a normative model of fear appeals. Journal of Marketing, 55(3), 36-45. doi: 10.2307/1252146

Verbeke, W., \& Bagozzi, R. P. (2002). A situational analysis on how salespeople experience and cope with shame and embarrassment. Psychology \& Marketing, 19(9), 713-741. doi: 10.1002/mar.10032

Vergara, S. C. (2008). Métodos de pesquisa em administração. São Paulo: Editora Atlas.

Verhoef, P. C., \& Sloot, L. M. (2006). Out-of-stock: reactions, antecedents, management solutions, and a future perspective. In M. Krafft \& M. K. Mantrala (Eds.), Retailing in the 21st Century (pp. 239-253). London: Springer Berlin Heidelberg.

Watson, D., \& Tellegen, A. (1985). Toward a consensual structure of mood. Psychological Bulletin, 98(2), 219-235. doi: 10.1037/0033-2909.98.2.219 


\section{Dados dos Autores}

\section{Giuliana Isabella}

Av. Prof. Luciano Gualberto, 908, Sala E-187, Cidade Universitária, 05508-010. São Paulo, SP, Brasil. E-mail: giuliana.isabella@gmail.com

Lucia Salmonson Guimarães Barros

Praia de Botafogo, 190, 22250-900, Rio de Janeiro, RJ, Brasil. E-mail: lucia.barros@fgv.br

José Afonso Mazzon

Av. Prof. Luciano Gualberto, 908, Sala E-187, Cidade Universitária, 05508-010, São Paulo, SP, Brasil. E-mail: jamazzon@usp.br 